\title{
Como interpretar e valorizar adequadamente 0 teste de anticorpos antinúcleo
}

\author{
How to interpret and appropriately appreciate the antinuclear antibody test
}

Alessandra Dellavance'; Luís Eduardo Coelho Andrade²

\begin{abstract}
unitermos resumo
Fator antinúcleo

Células HEp-2

Imunofluorescência indireta

Doenças auto-imunes

Atualmente, a pesquisa de anticorpos contra antígenos celulares, historicamente chamados de fator antinúcleo (FAN), tem requerido dos profissionais que trabalham (direta ou indiretamente) com o exame uma acurada e constante revisão dos paradigmas que norteiam a interpretação dos resultados obtidos. Os avanços metodológicos levaram a um aumento expressivo na sensibilidade do teste e, conseqüentemente, à diminuição de sua especificidade, fato comprovado pelo crescente número de exames positivos em indivíduos sabidamente hígidos. Há características peculiares, as quais usualmente são associadas aos auto-anticorpos observados em pacientes auto-imunes e em indivíduos não-autoimunes. O objetivo desta revisão é trazer uma abordagem sobre os pontos importantes, para a correta valorização dos achados do teste do FAN, que possa auxiliar na identificação de pacientes com doenças auto-imunes. É discutida a importância do título e do padrão de imunofluorescência na valorização de um teste positivo e no desdobramento da pesquisa de auto-anticorpos específicos. Também é feita uma revisão dos conceitos do Consenso Nacional para Padronização dos Laudos de FAN-HEp-2. Finalmente, é oferecida uma discussão sobre os possíveis significados do teste positivo de FAN em um paciente sem evidência objetiva de doença auto-imune.
\end{abstract}

abstract

The tradicional fluorescent antinuclear antibody test (ANA) has required constant update efforts from personel involved in performing and interpreting its results. The methodological advances have brought up a considerable improvement in the test's sensitivity and, consequentely, a decrease in its specificity. This has resulted in an increasing number of positive tests in apparently healthy subjects. However, there are some peculiar features associated with the auto-antibodies in patients with autoimmune diseases that are not present in those observed in healthy subjects. The objective of the present review is to bring an approach on the most important points to be considered in the analysis and evalution of an ANA test that might help in the identification of patients with autoimmune disease. Title and immunofluorescence pattern are discussed as important parameters and they are important in the evaluation of ANA and in the reflex demand for further tests for specific autoantibodies. The basic concepts of the National Consensus on Standardization of ANA-HEp-2 Report are posted. Finally, we explore the possible meanings of a positive ANA test in a patient without objective evidence of autoimmune disease.

key words

Antinuclear antibodies

HEp-2 cells

Autoantibodies

Autoimmune diseases

Serological markers

1. Pós-graduanda em nível de Doutorado na disciplina de Reumatologia pela Universidade Federal de São Paulo (UNIFESP); assessora cientifica do Setor de Imunologia do Fleury Medicina Diagnóstica. 2. Professor associado da disciplina de Reumatologia na UNIFESP; assessor médico do Setor de Imunologia do Fleury Medicina Diagnóstica. 


\section{Introdução}

O panorama científico atual é reflexo de rápidos e crescentes avanços metodológicos nas mais diferentes áreas da ciência e exige contínua reflexão sobre alguns paradigmas em todos os nichos da sociedade moderna. A prática médica sofre o impacto direto dessa evolução, o que tem aumentado significativamente as potencialidades de intervenção na saúde e também representado um desafio para o gerenciamento dos recursos destinados às diferentes áreas da medicina. No que diz respeito diretamente à medicina laboratorial, hoje freqüentemente são reportados laudos laboratoriais com grande número de informações, de extremo detalhamento, e que nem sempre traduzem de forma objetiva e inquestionável a condição de saúde de um paciente. Essa situação se torna particularmente crítica quando a evolução científico-tecnológica promove mudanças em exames laboratoriais que afetam parâmetros importantes para a interpretação clínica, como os valores preditivos positivo e negativo, a sensibilidade e a especificidade.

Ótimo exemplo desse tipo de situação é o exame para pesquisa de anticorpos antinúcleo (ANA) pela técnica de imunofluorescência indireta (IFI), também conhecido como fator antinuclear (FAN), em soro de pacientes com suspeita de doença auto-imune. Trata-se de um excelente exame de rastreamento de auto-anticorpos que, ao longo das últimas décadas, foi tecnicamente modificado de forma a conferir sensibilidade progressivamente maior. Como conseqüência, o teste ANA passou também a apresentar menor especificidade.

Atualmente, um dos fatos mais intrigantes na pesquisa de ANA está no número elevado de achados positivos em indivíduos aparentemente hígidos. Esse importante aspecto será abordado minuciosamente no decorrer deste texto.

Não resta dúvida de que a compreensão das peculiaridades atuais da pesquisa de ANA requer uma análise retrospectiva e histórica do exame para que o profissional tenha condição de responder seguramente à pergunta que freqüentemente se faz: como interpretar e valorizar adequadamente o teste de anticorpos antinúcleo?

Uma breve descrição dos fatos ocorridos nas últimas décadas nos auxiliará a encontrar algumas respostas para essa questão e certamente suscitará alguns questionamentos que ainda não podem ser respondidos.

A história dos anticorpos antinúcleo começa com Hargraves ${ }^{(20)}$, que demonstrou na década de 1940 a presença de material nuclear fagocitado em sangue de pacientes com lúpus eritematoso sistêmico (LES) (Figura 1). Tratava-se de anticorpos da classe $\lg G$ com reatividade contra desoxirribonucleoproteínas. Essa observação deu origem a um ensaio laboratorial altamente específico, que recebeu o nome de teste das células do lúpus eritematoso (células LE). Por algumas décadas, esse teste foi parte integrante dos critérios estabelecidos pelo Colégio Americano de Reumatologia (CAR) para classificação do $\operatorname{LES}^{(38)}$. O exame era caracteristicamente marcado por alta complexidade e subjetividade na interpretação, dificuldade em treinamento de profissionais para executar o ensaio, falta de reprodutibilidade e baixa sensibilidade.

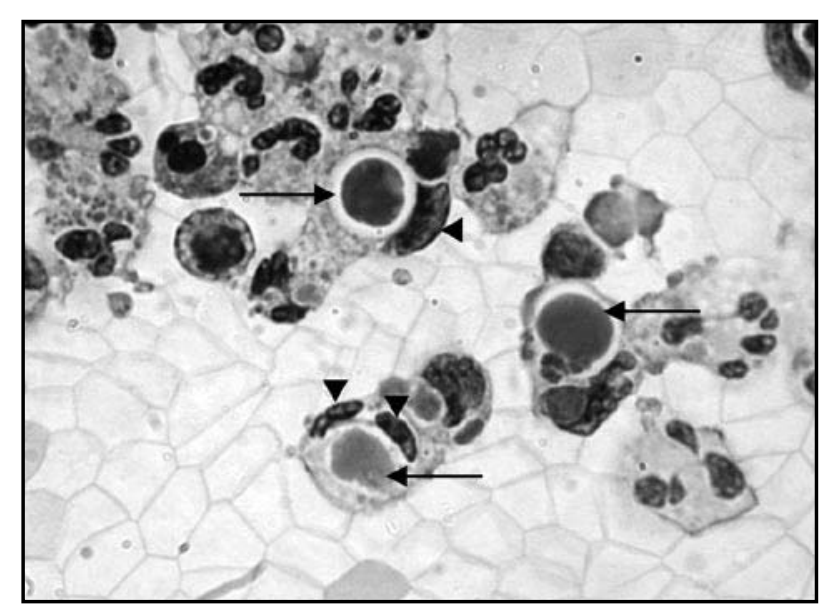

Figura 1 - Imagem gentilmente cedida pelo Dr. Victor Piana de Andrade (Setor de Anatomia Patológica do Fleury Medicina e Saúde). Setas longas apontam massas de cromatinas fagocitadas por neutrófilos. Cabeças de setas apontam núcleos íntegros de neutrófilos rechaçados pelas massas cromatínicas fagocitadas.

Por decisão do Conselho de Pesquisa e da Junta de Diretores do CAR $^{(24)}$, em 1997 a pesquisa de células LE foi eliminada como um dos critérios para a classificação de LES devido ao desenvolvimento de ensaios laboratoriais de execução metodológica menos complexa, mais reprodutiva e de maior sensibilidade em relação aos testes das células LE. Foram acrescentados como critérios alternativos outros auto-anticorpos considerados marcadores de LES, como anti-Sm e anti-DNA nativo.

Em meados da década de $1950^{(9)}$, a técnica de IFI passou a ser utilizada na triagem de ANA (ANA-IFI) no soro de pacientes com suspeita de doença auto-imune. O substrato antigênico da reação era corte de tecido de roedores ou imprint de fígado de camundongo, porém outras fontes antigênicas foram inicialmente utilizadas para esse fim, como esfregaço de leucócitos humanos. A técnica possibilitou a identificação de um universo mais amplo de auto-anticorpos que a pesquisa de células LE. Além disso, o ANA-IFI passou também a indicar a possível presença de alguns auto-anticorpos em pacientes com suspeita de outras 
doenças auto-imunes, como esclerose sistêmica e síndrome de Sjögren, o que não era possível com a pesquisa de células LE restrita a informações aplicadas apenas à suspeita de LES. É importante enfatizar que o teste não era mais específico de LES, mas poderia ser positivo em alguns pacientes com outras doenças reumáticas auto-imunes. Entretanto, com o uso desse substrato, um teste de ANA-IFI positivo, apesar de não mais específico para LES, ainda trazia maior possibilidade diagnóstica de LES que de outras enfermidades. $O$ aumento na sensibilidade, no entanto, resultou em diminuição substancial na especificidade até mesmo para o diagnóstico de doença reumática auto-imune, pois alguns indivíduos aparentemente hígidos (2\% a 4\%) passaram a apresentar resultados positivos pela técnica de ANA-IFI, o que era extremamente raro com o teste das células LE.

De uma maneira bastante prática, a informação dada pelo ANA-IFI resulta do reconhecimento de antígenos presentes no núcleo do hepatócito por auto-anticorpos presentes no soro de pacientes. A ligação antígeno/anticorpo revelada por anticorpos contra a gamaglobulina humana marcada com fluorocromo traduz-se na forma de padrões morfológicos ao microscópio que correspondem à distribuição topográfica dos respectivos auto-antígenos. No imprint de fígado de camundongo ou cortes de tecido de roedores, cinco padrões básicos de IFI podem ser visualizados e interpretados como nos mostra a Tabela 1.

Por se tratar de um exame destinado ao rastreamento de auto-anticorpos, a descrição dos padrões de IFI tem como objetivo direcionar o clínico a testes específicos que identificam o antígeno-alvo reconhecido por um determinado auto-anticorpo e complementam os achados preliminares do teste ANA-IFl, buscando uma associação clínica específica (Tabela 1). Isoladamente, o teste de ANA-IFI não permite definir precisamente o antígeno reconhecido e vincular o resultado encontrado a uma dada doença. Para esse fim, os testes tradicionalmente utilizados que permitem a identificação de auto-anticorpos em doenças reumáticas auto-imunes são a imunodifusão dupla de Outcherlony (IDD) ${ }^{(2)}$ para identificação de diversos antígenos (SS-A/Ro, SS-B/La, Sm, U1RNP, Jo-1, Scl-70, PM/Scl) e a imunofluorescência indireta com substrato específico, como Crithidia luciliae ${ }^{(1)}$ para detecção de anticorpos anti-DNA nativo. Mais recentemente têm sido desenvolvidos kits comerciais de ensaio imunossorvente ligado à enzima (ELISA) ${ }^{(4,35)}$ e hemagalutinação( ${ }^{(6)}$ para detectar alguns desses auto-anticorpos. Seu desempenho diagnóstico é altamente dependente da qualidade dos insumos e há possibilidade de resultados falso-positivos em virtude da excessiva sensibilidade desses dois métodos. Resultados positivos em níveis próximos ao valor de corte do ensaio devem ser valorizados com extrema cautela.

Nas últimas duas décadas passou-se a utilizar cada vez mais um outro substrato para realização do teste de ANA-IFI. Trata-se da célula HEp-2 (American Type Culture Collection CCL-23), que é uma linhagem de células tumorais derivadas de carcinoma de laringe humana cultivada em monocamadas sobre lâminas de vidro. Essas células provaram ser excelente substrato para oferta de auto-antígenos no ensaio ANA-IFI, apresentando uma gama de antígenos. Ademais, os elementos citológicos são grandes e bem evidenciados, contribuindo para uma ótima visibilização quando corados pelos auto-anticorpos.

Hoje, a célula HEp-2 praticamente substituiu os cortes ou imprint de fígado de roedores nos laboratórios clínicos em todo o mundo. Essa substituição inevitável deveu-se a múltiplos fatores, entre os quais o mais importante foi a excelente visibilidade de múltiplos padrões e a oferta de uma miríade de auto-antígenos inerente a esse substrato. Também contribuiu a facilidade de manuseio de cultivo celular comparado à manutenção de biotérios apropriados para a criação de animais em laboratórios de rotina. Um terceiro fator foi a padronização universal, já que os vários laboratórios em todo o mundo passaram a utilizar o

Tabela 1

Padrōes de IFI observados em imprint de fígado de camundongo ou cortes de tecido de

\begin{tabular}{|c|c|c|}
\hline $\begin{array}{l}\text { Periférico e } \\
\text { homogêneo }\end{array}$ & DNA nativo & $\begin{array}{l}\text { LES, LES induzido por drogas, artrite juvenil idiopática, síndrome } \\
\text { de Felty, esclerose sistêmica, CBP, hepatite auto-imune }{ }^{(18)}\end{array}$ \\
\hline Homogêneo & DNA nativo & $\begin{array}{l}\text { LES, LES induzido por drogas, artrite juvenil idiopática, síndrome de } \\
\text { Felty, esclerose sistêmica, cirrose biliar primária, hepatite auto-imu- } \\
\text { ne }\end{array}$ \\
\hline Pontilhado fino & SS-A/Ro e/ou SS-B/La & $\begin{array}{l}\text { Sindrome de Sjögren, LES, LES neonatal, LES cutâneo, AR, miosite e } \\
\text { esclerose sistêmica, polimiosite }{ }^{(36)}\end{array}$ \\
\hline Pontilhado grosso & Sm e/ou RNP & LES, DMTC, esclerose sistêmica ${ }^{(30)}$ \\
\hline Nucleolar & Antígenos nucleolares & Esclerose sistêmica, polimiosite/ES, polimiosite/dermatomiosite ${ }^{8}$ \\
\hline
\end{tabular}

LES: lúpus eritematoso sistêmico; AR: artrite reumatóide; DMTC: doença mista do tecido conectivo; CBP: cirrose biliar primária. 
mesmo tipo de substrato. Atualmente, diversos fabricantes fornecem lâminas comerciais com células HEp-2 fixadas com excelente qualidade, contribuindo para a aplicação técnica uniforme entre os laboratórios de análises clínicas.

Padrões de fluorescência associados aos antígenos situados nos diferentes compartimentos celulares (núcleo, nucléolo, citoplasma, placa cromossômica metafásica e aparelho mitótico) que não estavam disponibilizados em tecidos de roedores passaram a ser observados (Figuras $\mathbf{2}$ e $\mathbf{3}$ ). Outra característica fundamental é que a célula HEp-2 expressa alguns auto-antígenos relevantes que não são expressos em tecidos de roedores. $\mathrm{O}$ exemplo mais eloqüente é o do complexo SS-A/Ro, que invariavelmente está ausente de cortes de roedores ${ }^{(21)}$. Assim, um soro monoespecífico anti-SS-A/Ro dá resultado negativo no ANA-IFI em tecido de roedores e é francamente positivo quando se usa a célula HEp-2.

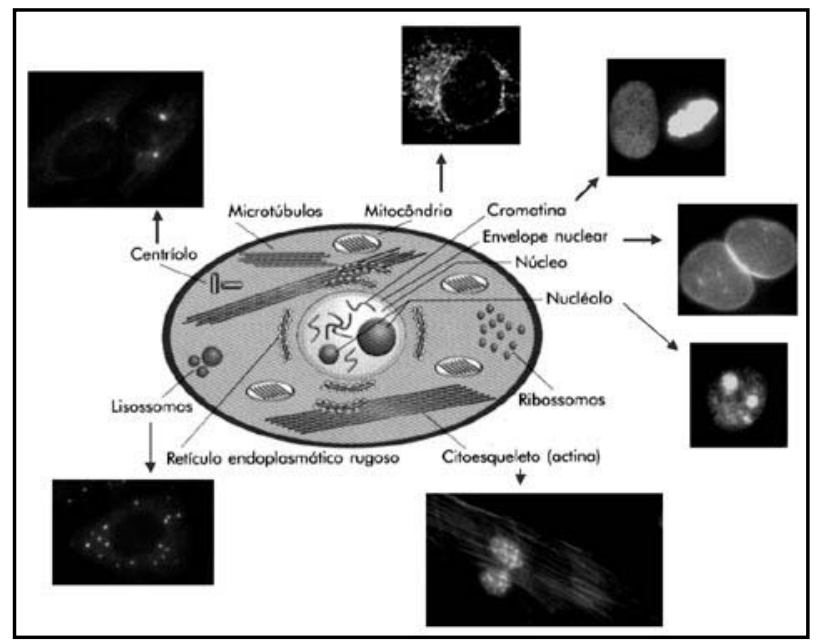

Figura 2 - Imagem esquemática de núcleo celular em interfase e exemplos de padrões de ANA-HEP-2 associados a algumas estruturas celulares

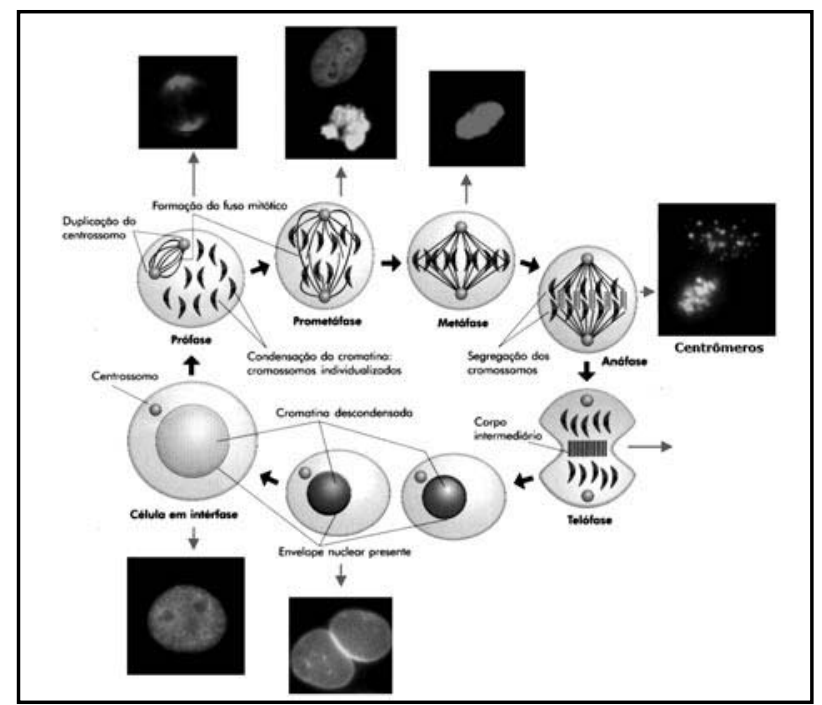

Figura 3 - Imagem esquemática de ciclo celular e exemplos de padrões de ANAHEp-2 associados às diferentes fases mitóticas
Finalmente, como se trata de uma cultura tumoral em constante proliferação, estão presentes células nas diferentes fases do ciclo celular, expressando antígenos exclusivos da mitose (Figura 3) como, por exemplo, o antígeno nuclear de proliferação celular (PCNA), reconhecido por auto-anticorpos presentes em $2 \%$ a $5 \%$ dos pacientes com $\operatorname{LES}(7,37)$.

Além disso, a melhor visibilidade dos diferentes compartimentos da célula resultou num espectro ainda maior de padrões de fluorescência oferecidos pelo testes ANA-IFI. Os cinco padrões básicos de ANA-IFI observados no ensaio com imprint ou corte de fígado de roedores deram lugar a mais de 20 padrões que podem ser identificados e reportados nos exames de ANA com emprego de células HEp-2 (ANA-HEp2). Alguns desses padrões de IFI e suas possíveis associações antigênicas e clínicas estão apresentados na Tabela 2.

$O$ resultado da maior oferta de antígenos levou a expressivo aumento na sensibilidade do ensaio. Aumentou-se o rol de auto-anticorpos passíveis de serem detectados e reduziu-se o limiar de concentração sérica a partir do qual os mesmos passam a ser detectados. Portanto, níveis baixos de auto-anticorpos por vezes não detectáveis no teste ANAIFI com tecidos de roedores passaram a ser detectáveis no teste ANA-HEp-2.

Conseqüência direta desse aumento na sensibilidade foi uma considerável perda de especificidade do teste, o que resultou na necessidade de uma interpretação bastante criteriosa dos achados sorológicos ${ }^{(16)}$. Um dos fatos atuais mais intrigantes na pesquisa de ANA-HEp-2 é o número elevado de achados positivos em indivíduos aparentemente hígidos. Na literatura essa frequêencia exibe ampla variação (Tabela 3), provável reflexo das diferenças étnicas, ambientais e metodológicas (substrato utilizado, conjugado, microscópio).

Assim como no ANA-IFI, a interpretação de um resultado positivo do teste ANA-HEp-2 pode ser auxiliada pela detecção de auto-anticorpos específicos associados ao padrão encontrado, como mencionado anteriormente. Por exemplo, a demonstração de anticorpos anti-DNA nativo ou antinucleossomo é fortemente indicativa de LES. Anticorpos anti-Jo-1 ${ }^{(14)} \mathrm{e}$ anti-Scl-70 ${ }^{(23)}$ são marcadores de polimiosite e esclerose sistêmica, respectivamente. Portanto, o encontro desses ou de outros marcadores específicos contribui para a definição mais acurada da valorização de um resultado positivo de ANA-HEp-2. Em contrapartida, a ausência desses marcadores não invalida, mas diminui a força do achado de ANA-HEp-2, especialmente se este for de características pouco específicas e não houver contrapartida clínica ou laboratorial de doença auto-imune sistêmica. 
Tabela 2 Exemplos de padrões de ANA-HEp-2, auto-antígenos associados e possíveis correlações clínicas

\begin{tabular}{|c|c|c|}
\hline Padrão de IFI-ANA & Auto-antígeno(s) associado(s) & Correlação clínica \\
\hline \multirow[t]{6}{*}{ Nuclear homogêneo } & DNA nativo & LES \\
\hline & DNA de hélice simples & $\begin{array}{l}\text { Artrite juvenil idiopática; LES induzido } \\
\text { por drogas e LES idiopático }\end{array}$ \\
\hline & Histona (H1, H2A, H2B, H3, e H4) & LES idiopático; LES induzido por drogas; \\
\hline & & $\begin{array}{l}\text { AR; sindrome de Felty; artrite juvenil } \\
\text { idiopática; esclerose sistêmica; cirrose }\end{array}$ \\
\hline & & biliar primária; hepatite auto-imune \\
\hline & Nucleossomo & LES \\
\hline \multirow[t]{2}{*}{ Nuclear pontilhado fino } & La/SS-B & $\begin{array}{l}\text { Síndrome de Sjögren, LES, LES neonatal, } \\
\text { LES cutâneo }\end{array}$ \\
\hline & Ro/SS-A & $\begin{array}{l}\text { Síndrome de Sjögren, LES, LES cutâneo, } \\
\text { LES neonatal, AR, miosite e esclerose } \\
\text { sistêmica, polimiosite }\end{array}$ \\
\hline \multirow{2}{*}{$\begin{array}{l}\text { Nuclear pontilhado } \\
\text { grosso }\end{array}$} & Sm & LES \\
\hline & U1-RNP (22, 34 e 70kDa) & DMTC, LES, esclerose sistêmica. \\
\hline $\begin{array}{l}\text { Nuclear pontilhado } \\
\text { grosso reticulado }\end{array}$ & Ribonucleoproteínas heterogêneas (hnRNP) & $\begin{array}{l}\text { LES, DMTC, outras doenças reumáticas, } \\
\text { doenças inflamatórias crônicas e mesmo } \\
\text { indivíduos hígidos }\end{array}$ \\
\hline Membrana nuclear & Lamins, Lamin B, gp210 & $\begin{array}{l}\text { Doenças reumáticas auto-imunes, } \\
\text { hepatopatias, doenças virais e também } \\
\text { indivíduos hígidos }\end{array}$ \\
\hline Raros pontos nucleares & p80 coilina $(80 \mathrm{kDa})$ & $\begin{array}{l}\text { Síndrome de Sjögren, doenças } \\
\text { inflamatórias, indivíduos hígidos }\end{array}$ \\
\hline $\begin{array}{l}\text { Múltiplos pontos } \\
\text { nucleares }\end{array}$ & Sp-100 & CBP \\
\hline Nuclear pleomórfico & $\begin{array}{l}\text { Antígenos de célula em proliferação PCNA } \\
(34 \mathrm{kDa}) \text {, CENP-F (340kDa) }\end{array}$ & LES, condições neoplásicas \\
\hline Centromérico & $\begin{array}{l}\text { Proteínas associadas ao centrômero (CENP- } \\
\text { A de } 17 \mathrm{kDa} \text {, CENP-B de } 80 \mathrm{kDa} \text { e CENP-C de } \\
140 \mathrm{kDa} \text { ) }\end{array}$ & CREST, esclerose sistêmica, CBP \\
\hline \multirow[t]{4}{*}{ Nucleolar } & $\begin{array}{l}\text { Fibrilarina (34kDa) (nucleolar grumoso } \\
\text { puro) }\end{array}$ & Esclerose sistêmica \\
\hline & $\begin{array}{l}\text { PMScl (20-110kDa) (nuclear homogêneo e } \\
\text { nucleolar pontilhado fino) }\end{array}$ & $\begin{array}{l}\text { Polimiosite/ES; polimiosite/ } \\
\text { dermatomiosite, esclerose sistêmica }\end{array}$ \\
\hline & $\begin{array}{l}\text { RNA polimerase I ( } 10 \text { a } 220 \mathrm{kDa} \text { ) (nucleolar } \\
\text { pontilhado e pontos isolados na placa } \\
\text { metafásica) }\end{array}$ & Esclerose sistêmica \\
\hline & $\begin{array}{l}\text { Scl-70 (70 e } 86 \mathrm{kDa} \text { ) (nuclear e nucleolar } \\
\text { pontilhado fino) }\end{array}$ & $\begin{array}{l}\text { Esclerose sistêmica, esclerodermia } \\
\text { limitada, esclerodermia difusa }\end{array}$ \\
\hline $\begin{array}{l}\text { Citoplasmático } \\
\text { pontilhado fino denso }\end{array}$ & Proteína P ribossomal & LES \\
\hline $\begin{array}{l}\text { Citoplasmático } \\
\text { pontilhado reticulado }\end{array}$ & Antígenos mitocondriais & CBP \\
\hline
\end{tabular}

LES: lúpus eritematoso sistêmico; AR: artrite reumatóide; DMTC: doença mista do tecido conectivo; CBP: cirrose biliar primária; CREST: acrônimo das principais características clínicas de uma variação da esclerodermia (calcinose, fenômeno de Raynaud, distúrbios da motilidade esofágica, esclerodactilia e telangiectasia). 


\begin{tabular}{|c|c|c|}
\hline População estudada & $\begin{array}{l}\text { Frequiência de FAN posi- } \\
\text { tivo } \\
\text { em indivíduos hígidos }\end{array}$ & Autor \\
\hline 597 trabalhadores hígidos de um hospital urbano no Japão & $20 \%$ & Watanabe et al. $(2004)^{(41)}$ \\
\hline 500 doadores de sangue no Hemocentro de São Paulo & $22,6 \%$ & Fernandez et al. $(2003)^{(15)}$ \\
\hline 259 indivíduos com idade superior a 65 anos (UNIFESP) & $12,8 \%$ & Santos et al. $(1997)^{(33)}$ \\
\hline Indivíduos entre 6 meses e 20 anos (UNIFESP) & $12,6 \%$ & Hilario et al. $(2004)^{(22)}$ \\
\hline
\end{tabular}

Essas considerações são de valor inestimável para uma adequada interpretação do teste ANA-HEp-2 e reforçam a necessidade de uma reflexão cuidadosa sobre o contexto histórico do exame que partiu de um achado de extrema especificidade e baixa sensibilidade (células LE em pacientes lúpicos), migrou para o ANA-IFI em tecido animal, um substrato limitado na expressão antigênica, e culminou no ANAHEp-2, com riqueza extrema em expressão antigênica.

Diante desse novo panorama algumas considerações merecem a nossa atenção:

- qual é a relevância clínica dos padrões de ANA-HEp-2?

- qual é a relevância clínica dos títulos de ANA-HEp-2?

- existe padronização interlaboratorial para a composição dos laudos laboratoriais?

\section{A relevância clínica dos padrões de ANA-HEp-2}

Como mencionado anteriormente, o padrão de IFI reflete a distribuição topográfica dos antígenos reconhecidos pelos auto-anticorpos em um determinado soro. Essa associação é mais refinada no caso das células HEp-2, em função do alto grau de detalhamento citológico das mesmas e pelo fato de que elas exibem claramente o comportamento dos vários auto-antígenos ao longo das fases do ciclo celular. $\mathrm{A}$ identificação apropriada dos padrões de IFI no ANA-HEp-2 fornece uma razoável indicação da possível especificidade do(s) auto-anticorpo(s) detectado(s) ${ }^{(17)}$. Assim como no ANA-IFI em tecido de roedores, testes complementares são essenciais para verificar se a reatividade encontrada no teste ANA-HEp-2 corresponde ao auto-anticorpo sugerido pelo padrão de IFI.

Auto-anticorpos contra alguns antígenos têm associação bastante específica a determinadas doenças auto-imunes ou ao estado de auto-imunidade em si, enquanto outros ocorrem indiscriminadamente em indivíduos auto-imunes e não auto-imunes. Dessa forma, determinados padrões de fluorescência são mais específicos de doença auto-imune, enquanto outros ocorrem com freqüência em indivíduos sadios ou em pacientes com outras enfermidades não auto-imunes. O citoplasma celular, por exemplo, é rico em proteínas para as quais auto-anticorpos naturais apresentam afinidade moderada; não raramente, o soro de indivíduos sadios apresenta reatividade moderada contra o citoplasma das células HEp-2, evidenciando diferentes padrões de $\mathrm{IFI}^{(4)}$.

Estudos de biologia molecular e celular permitiram estabelecer a associação de diversos padrões de fluorescência, domínios celulares e seus respectivos auto-antígenos. Assim, o padrão nuclear pontilhado grosso, por exemplo, representa exatamente o mapa de distribuição das proteínas envolvidas no processamento (splicing) do RNA mensageiro ${ }^{(10)}$, também conhecido como spliceosome. Ocorre que as principais proteínas do spliceosome são exatamente aquelas reconhecidas pelos anticorpos anti-Sm (proteínas B, B', D, D', E, F e G) ${ }^{(32)}$ e anti-U1-RNP (proteínas A, C e 70kDa) ${ }^{(30)}$. Portanto, o padrão nuclear pontilhado grosso é virtualmente específico de anticorpos anti-Sm e/ou anti-U1-RNP. Clinicamente, anticorpos anti-Sm estão fortemente associados ao LES, enquanto os anticorpos anti-RNP são mais freqüentemente observados na doença mista do tecido conectivo (DMTC) e no LES. Vale ressaltar que o padrão nuclear pontilhado grosso reticulado, muitas vezes confundido com o pontilhado grosso, tem significado imunológico e clínico inteiramente diverso. Da mesma forma, o padrão nuclear homogêneo representa a distribuição da cromatina no núcleo e, portanto, tende a ser ocasionado por anticorpos contra o DNA nativo, nucleossomo ou histonas. Clinicamente, anticorpos anti-DNA nativo e antinucleossomo são considerados marcadores de LES.

Outros padrões observados no teste ANA-IFI, também associados especificamente a determinados domínios nucleares e seus respectivos antígenos, não são considerados específicos de uma dada doença. Isso decorre do fato de que os anticorpos contra esses antígenos não são estritamente associados a 
uma condição auto-imune ou mesmo à auto-imunidade em geral. Alguns exemplos dessa situação são o padrão de raros pontos nucleares isolados, correspondente aos anticorpos anti-p80-coilina ${ }^{(3)}$, e o padrão centriolar ${ }^{(8)}$, correspondente a anticorpos anticentríolo. Quando em baixos títulos, também são pouco relevantes os padrões citoplasmático polar (Golgi), aparelho mitótico e nuclear pontilhado grosso reticulado. Mesmo o padrão centromérico, considerado marcador de formas limitadas de esclerose sistêmica, tem pouca especificidade quando encontrado em títulos baixos.

Para comprovar essa afirmativa, Leser et al. ${ }^{(28)}$ realizaram um levantamento e demonstraram a importância da associação entre o padrão de IFI e o estado clínico. $O$ trabalho foi baseado em uma amostragem aleatória de 394 pacientes com ANA-HEp-2 positivo recrutados da rotina de um laboratório clínico e com informações clínicas obtidas de forma sistemática junto aos médicos. De acordo com um protocolo preestabelecido, os pacientes foram classificados em dois grupos: um de indivíduos com indícios de enfermidades auto-imunes e outro de indivíduos sem qualquer evidência de auto-imunidade. Como pode ser observado na Figura 4, os padrões nuclear pontilhado grosso $(\mathrm{PG})$ e homogêneo $(\mathrm{H})$ associaram-se quase exclusivamente a pacientes com enfermidades autoimunes. Em contrapartida, os padrões nuclear pontilhado fino denso (PFd) e nuclear pontilhado grosso reticulado (PGR) associaram-se predominantemente a indivíduos sem qualquer evidência de auto-imunidade. Outros padrões de fluorescência apresentaram graus de associação intermediária. Ao se conjugarem as informações de padrão de fluorescência e título observou-se, para alguns padrões, que a associação com ausência de auto-imunidade foi real apenas em títulos baixos. Esse foi o caso do padrão nuclear pontilhado fino (PF) e do PGR. Outros, por sua vez, mantiveram sua associação com ausência de auto-imunidade em títulos baixos e altos, como foi o caso do padrão PFd.

Os achados de Leser et al. foram corroborados por Goto et al.(19), que estudaram um grupo de 1.306 japoneses hígidos trabalhadores em um hospital. Nessa população, $3,7 \%$ dos indivíduos apresentavam anticorpos anti-p80 coilina, sem qualquer evidência de auto-imunidade. Um outro exemplo está no padrão citoplasmático de pontos isolados, estudado por Laurino et al.(27), e presente em indivíduos sem evidência de auto-imunidade, mas também em indivíduos com acometimento de doenças auto-imunes sistêmicas e órgão-específicas.

Não resta dúvida de que essas considerações afetam diretamente a interpretação dos resultados na rotina clínica. Esse aspecto pode ser apreciado em outro levantamento com importante impacto, realizado num grande laboratório clínico na cidade de São Paulo ${ }^{(13)}$. Entre 30.728 amostras encaminhadas para triagem de auto-anticorpos em ANA-HEp-2, no período de janeiro de 2001 a janeiro de 2003, 13.641 (44\%) apresentavam reatividade nuclear. Obviamente, essa fração está bem acima da expectativa de doenças auto-imunes em uma casuística geral de pacientes. Portanto, o padrão de reatividade encontrado poderia refletir parcialmente o perfil de ANA-HEp-2 apresentado por indivíduos não auto-imunes. Entre esses $44 \%$ os padrões mais prevalentes foram o PF e o PFd. Os títulos observados foram predominantemente baixos para o padrão nuclear $\mathrm{PF}$, enquanto o padrão nuclear PFd apresentou maior freqüência em títulos mais altos. Ao todo, o padrão PFd

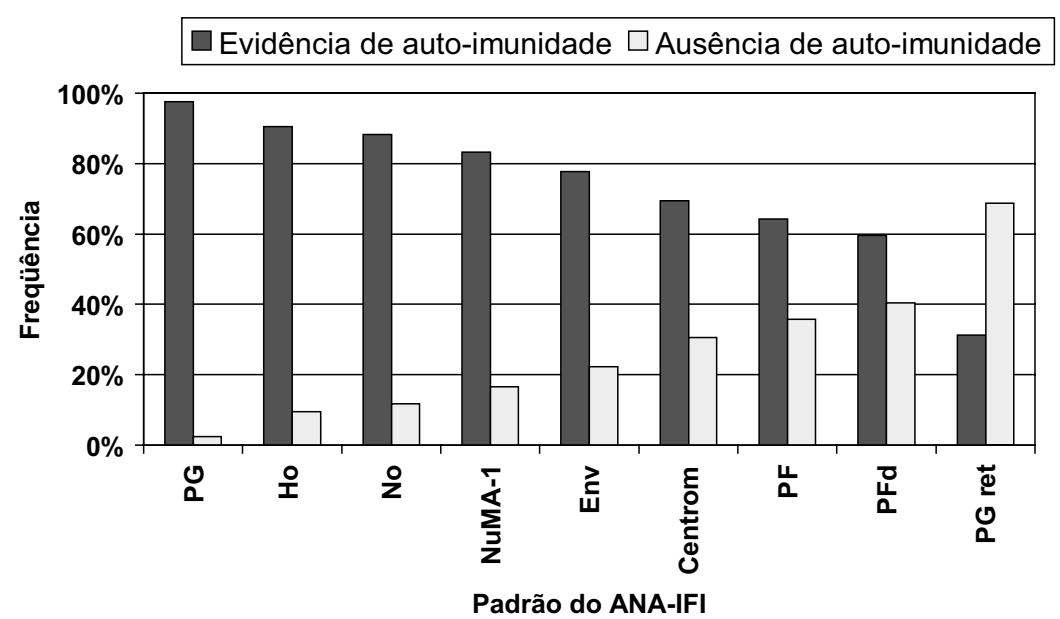

Figura 4 - Distribuição do padrão de fluorescência no teste de anticorpos antinúcleo em células HEp-2 (ANA-IFI) em 389 pacientes de acordo com a presença e a ausência de evidência de auto-imunidade

PG: pontilhado grosso; Ho: homogêneo; No: nucleolar; NuMA-1: aparelho mitótico característico da proteína NuMA-1; Env: envelope nuclear; Centrom: centromérico; PF: pontilhado fino; PFd: pontilhado fino denso; PGR: pontilhado grosso reticulado. Adaptado de Leser et al. ${ }^{(28)}$. 
representou cerca de um terço das amostras com positividade nuclear.

Curiosamente, o padrão PFd era desconhecido até há pouco tempo, talvez em função de sua baixa representatividade nas casuísticas de pacientes auto-imunes. Entretanto, sua alta freqüência em indivíduos não auto-imunes torna o seu reconhecimento importante para que se possam apreciar adequadamente os achados do teste de ANA-HEp-2. A caracterização do antígeno responsável pela expressão do padrão PFd evidenciou forte associação com a especificidade imunológica anti-LEDGF/p75(34). O auto-antígeno alvo desses anticorpos, a proteína LEDGF, é um fator de transcrição fortemente ligado à cromatina e considerado um importante fator de sobrevivência celular. Esse auto-antígeno tem sua expressão aumentada em condições de estresse celular. Em nosso meio, Dellavance et al. confirmaram a forte associação do padrão PFd em células HEp-2 e a reatividade contra a proteína LEDGF/p75. Na casuística de Dellavance et al. apenas 18,5\% dos pacientes com padrão PFd apresentavam algum tipo de doença reumática auto-imune, e a maioria não apresentava qualquer indício de auto-imunidade. Nesse estudo havia também informação pregressa sobre dados sorológicos de 40 desses casos com padrão PFd por um período de até quatro anos, observando-se que 37 (93\%) mantiveram títulos altos de anticorpos para esse auto-antígeno. Portanto, trata-se de uma resposta sorológica duradoura, embora não específica de auto-imunidade.

Achados semelhantes foram encontrados por Watanabe et al. (2004)(41), que estudaram 597 trabalhadores hígidos de um hospital urbano no Japão (142 homens e 455 mulheres) para verificar a freqüência de anti-LEDGF/p75, responsável pelo padrão PFd. Para isso utilizaram ANAHEp2, WB e método imunoenzimático com LEDGF/p75 recombinante. Pela técnica de ANA-HEp-2 foi verificado que $20 \%$ dos indivíduos apresentaram reatividade nuclear e, destes, 64 apresentaram o padrão nuclear PFd, o que representa $53 \%$ dos casos positivos observados.

\section{A relevância clínica dos títulos de IFI-HEp-2}

Um segundo ponto a ser considerado é o título do ANA-HEp-2, muito embora seu valor seja relativo. Em geral, os pacientes auto-imunes tendem a apresentar títulos moderados ( $1 / 160$ e $1 / 320)$ e elevados $(\geq 1 / 640)$, enquanto os indivíduos sadios com ANA-HEp-2 positivo tendem a apresentar baixos títulos (1/80) havendo, no entanto, exceções de ambos os lados.
Nesse sentido, podemos destacar um estudo multicêntrico realizado por Tan et al. ${ }^{(38)}$ com pessoas de 20 a 60 anos. Em indivíduos hígidos observou-se relação inversa entre a freqüência de reações positivas e o título da reação: 1/40 em $31,7 \%$ dos indivíduos; $1 / 80$ em 13,3\%; 1/160 em 5\% e $1 / 320$ em $3,3 \%$.

Em outro estudo que tinha como objetivo a avaliação do significado clínico do título do ANA-HEp-2, Vaile et al. ${ }^{(40)}$ analisaram 320 soros selecionados de dois laboratórios clínicos por apresentarem títulos maiores que ou iguais a 1/640 e informações clínicas confiáveis. Entre eles, 56\% apresentavam diagnóstico de LES ou doenças auto-imunes, mas $44 \%$ não apresentavam quaisquer evidências de auto-imunidade. Alguns dos últimos apresentavam títulos de 1/5.120 ou 1/10.240. Embora esse estudo aponte claramente que altos títulos de ANA-HEp-2 não implicam necessariamente em auto-imunidade, não foi feita análise comparativa com pacientes apresentando títulos baixos. É possível que entre eles a porcentagem de pacientes sem evidência de auto-imunidade seja maior. Nesse sentido, cabe observar que no estudo de FAN em população geriátrica brasileira, conduzido por Santos et al. ${ }^{(33)}$, observou-se que a freqüência de títulos de FAN considerados altos em indivíduos hígidos acima de 65 anos de idade foi significativamente maior que nos controles entre 20 e 40 anos.

\section{Padronização interlaboratorial para a composição dos laudos laboratoriais}

A rápida e crescente difusão do uso das células HEp-2 em todo o mundo, tanto pela simplicidade metodológica como pelo fácil acesso a diferentes fornecedores, rapidamente evidenciou a necessidade de padronização na execução do ensaio e na interpretação dos padrões de IFI. Em nosso país, essa constatação conduziu vários profissionais à realização de um consenso nacional para emissão de laudos de FAN com a finalidade de padronizar os procedimentos e a nomenclatura referentes ao teste de ANA-HEp-2 nos vários laboratórios em território nacional. Os encontros foram realizados em Goiânia, em 2000 e em 2002, sob a coordenação do Professor Paulo Luiz Carvalho Francescantonio, da Universidade Católica de Goiás ${ }^{(12)}$. O resultado desses encontros foi a definição da diluição das amostras na triagem, a homogeneização das terminologias empregadas nos laudos, a padronização da descrição dos padrões observados nos diferentes compartimentos celulares, o estabelecimento de possíveis associações clínicas, a veiculação de material didático para treinamento de profissionais 
que realizam a leitura em microscopia, a troca contínua de informações entre diferentes centros que realizam o ANAHEp-2 e a alteração do nome do teste (FAN) para "pesquisa de anticorpos contra antígenos celulares".

Para o laudo final do exame, a sugestão do consenso é que o resultado seja subdividido na descrição do padrão de fluorescência em cinco compartimentos celulares: nuclear, nucleolar, citoplasmático, aparelho mitótico e placa cromossômica metafásica. $O$ consenso recomenda também que seja acrescentada ao laudo uma nota interpretativa, procurando traduzir o possível significado clínico e imunológico dos padrões observados na amostra.

Considerando a relevância do título e do padrão observados na análise da IFI com soro de pacientes sob suspeita de doença auto-imune, os laudos que seguem o modelo de organização proposto pelo consenso auxiliam o clínico na decisão sobre a valorização e a interpretação adequadas do resultado obtido. Cabe, no entanto, aos laboratórios de rotina estabelecer critérios extremamente rígidos com relação aos controles de qualidade da reação, manutenção preventiva contínua dos microscópios, titulação criteriosa dos conjugados, atualização continuada dos profissionais que realizam a análise da reação de IFI e definição de padrões e títulos. Fica evidente a necessidade de todos os profissionais envolvidos com a execução e a aplicação do FAN-HEp-2 possuírem completo conhecimento de características e limitações do teste para que laudos bem avaliados auxiliem de fato o paciente.

\section{Como interpretar um resultado positivo de ANA-HEp-2 em um paciente sem evidência clínica de doença auto-imune}

Diante de todos os aspectos abordados é importantíssimo ressaltar a problemática realidade existente no crescente número de pedidos indiscriminados do teste ANA-HEp-2 e de outros auto-anticorpos na prática clínica. Isso leva a situações conflitantes em que resultados positivos do ANAHEp-2 são confrontados com dados clínicos inconsistentes. A Tabela 4 sintetiza as possibilidades de interpretação de um teste positivo de ANA-HEp-2 e pode ser extrapolada para vários outros auto-anticorpos.

O impasse ocorre quando não há qualquer evidência clínica e/ou laboratorial consistente de doença auto-imune sistêmica. Para a correta interpretação desse achado é importante ter em mente que o fenômeno de auto-imunidade não é exclusivo de estados patológicos. De fato, existe certo grau de auto-imunidade fisiológica que se inicia no período intrauterino e persiste ao longo de toda a vida. Esse fenômeno está sobejamente confirmado pela demonstração dos auto-anticorpos naturais pelo grupo de Avrameas et al. ${ }^{(26)}$. Portanto, uma primeira interpretação é de que o achado do auto-anticorpo representa um "incidentaloma"(25), evento cada vez mais freqüente com o advento de recursos diagnósticos extremamente sensíveis. Situação análoga é observada hoje com os exames de imagem ultra-sensíveis, que freqüentemente revelam achados anatômicos sem contrapartida clínica evidente.

Outro ponto a se considerar é que o nível de auto-imunidade fisiológica, ou basal, pode flutuar na dependência de sobrecargas a que o sistema imunológico seja exposto. Está bem demonstrada a presença de auto-anticorpos desencadeada transitoriamente por infecções, por medicamentos e por neoplasias. Nosso grupo demonstrou claramente alta prevalência de auto-anticorpos em pacientes infectados pelo vírus da imunodeficiência humana (HIV) e por outros vírus linfotrópicos ${ }^{(29)}$. Portanto, outra consideração a ser feita ante um paciente com um achado positivo de ANA-HEp-2 refere-se à possibilidade de infecções virais recentes, uso de medicamentos e processos neoplásicos.

\section{Tabela 4 Possibilidades de interpretação de um teste positivo de ANA-HEp-2}

- Associação evidente com uma condição auto-imune

- Nenhuma associação evidente com uma condição auto-imune

- Incidentaloma?

- Auto-anticorpos associados a doenças inflamatórias crônicas?

- Distúrbio auto-imune transitório?

- Infecção?

- Drogas?

- Câncer?

- Traço familiar de auto-imunidade?

- Manifestação mínima de um espectro de condições auto-imunes?

- Manifestação precoce de uma doença auto-imune incipiente? 
Várias evidências demonstram que os auto-anticorpos freqüentemente precedem a eclosão clínica das doenças auto-imunes ${ }^{(5)}$. Um teste ANA-HEp-2 positivo pode preceder o aparecimento clínico do LES em até nove anos. Cerca de $80 \%$ dos pacientes com LES apresentam ANA-HEp- 2 positivo antes do aparecimento dos primeiros sintomas. O mesmo é válido, embora em menor porcentagem, para os vários autoanticorpos específicos dessa enfermidade, como anti-DNA nativo e anti-Sm. Portanto, outra possibilidade a se considerar em presença de um achado clinicamente inconsistente de ANA-HEp-2 positivo é de que o paciente poderá vir a desenvolver uma doença auto-imune nos próximos anos.

No entanto, alguns indivíduos podem seguir décadas com auto-anticorpos circulantes sem desenvolver qualquer sinal de enfermidade auto-imune. Deane et al. (1995)(11) acompanharam 31 crianças com FAN positivo, queixas musculoesqueléticas inespecíficas e nenhuma evidência objetiva de doença auto-imune à apresentação ao serviço. A maioria apresentava títulos inferiores a 1/640, mas algumas apresentavam títulos de $1 / 1.280$ ou $1 / 2.560$. Após um período médio de 37 meses, somente uma criança evoluiu para doença auto-imune, especificamente hepatite autoimune. As demais apresentaram desaparecimento (81\%) ou melhora (16\%) dos sintomas. Em nosso meio, um estudo prospectivo, realizado em uma coorte de pacientes geriátricos, evidenciou títulos de FAN iguais ou superiores a 1/40 em 8,8\% de 259 indivíduos sem evidência de manifestações auto-imunes. Alguns desses indivíduos apresentaram títulos maiores que ou iguais a 1/1.280. $O$ acompanhamento deles por cinco anos mostrou estabilidade do padrão e do título do FAN sem que houvesse desenvolvimento de sinais de auto-imunidade especificamente associada à presença de anticorpos antinúcleo ${ }^{(22)}$.

Sabe-se que as doenças auto-imunes apresentam importante componente genético. É comum que os familiares de primeiro grau de pacientes com doenças auto-imunes apresentem a mesma enfermidade que o probando ou outras doenças auto-imunes. Por vezes, os familiares apresentam apenas formas frustras que não permitem diagnóstico definido. Está aumentada a freqüência de auto-anticorpos em familiares de pacientes com doenças auto-imunes. Embora não tão acentuadamente como as doenças genéticas monogênicas, as doenças auto-imunes de caráter poligênico apresentam maior incidência em familiares de primeiro grau. Portanto, outra possibilidade a se considerar em face de um achado clinicamente inconsistente de ANA-HEp-2 positivo é que ele represente um traço espúrio de autoimunidade familiar.
Deve-se também ter em mente o caráter espectral das doenças auto-imunes. Há formas completas e graves, formas intermediárias e formas leves e incompletas. Portanto, há que se considerar ainda a possibilidade de que um auto-anticorpo isolado represente a mínima manifestação espectral de uma condição auto-imune não claramente manifesta.

Em suma, perante um resultado positivo de ANA-HEp-2 é imprescindível que haja verificação da existência de evidência clínica ou laboratorial de doença auto-imune sistêmica. Além do exame clínico apurado é importante verificar possíveis alterações em hemograma, urina I, proteína C-reativa e velocidade de hemossedimentação (VHS), que podem ser considerados extensões do exame clínico. Sintomas vagos, como artralgia e astenia, com exames laboratoriais gerais normais não são suficientes para oferecer subsídio para um achado laboratorial de ANA-HEp-2 em título baixo e com padrão de fluorescência pouco específico. Por outro lado, é sabido que algumas vezes as enfermidades auto-imunes manifestam-se inicialmente por sintomas vagos e pouco específicos. Nesse sentido, é bom lembrar que os auto-anticorpos podem preceder em meses ou anos a eclosão clínica de uma doença auto-imune. É importante também considerar a possibilidade de um estímulo imunológico transitório como causa do ANA-HEp-2 positivo. Isso é particularmente verdadeiro no contexto de infecções virais, como Epstein-Barr, citomegalovírus e parvovírus.

Entre as várias possíveis interpretações de um resultado positivo do teste ANA-HEp-2 incluem-se uma evidente associação com doença auto-imune, um traço incompleto de diátese auto-imune familiar, um achado precoce de doença auto-imune, um distúrbio imunológico transitório (infecção, droga, (âncer) e uma manifestação mínima de doença autoimune espectral. A análise criteriosa de todo o contexto clínico é fundamental para a correta valorização desse achado. Muitas vezes impõe-se monitoração prospectiva por algum tempo para se detectar uma possível evolução para autoimunidade clínica. Em todos os cenários é fundamental tranqüilizar o paciente, muitas vezes ansioso pelo estigma de um resultado positivo do teste ANA-HEp-2.

Concluindo, o exame FAN-HEp-2 conta com características relacionadas a sensibilidade, especificidade e valores preditivos que exigem obrigatoriamente conhecimento extremamente apurado do clínico para uma interpretação correta dos laudos liberados pelos laboratórios clínicos. Considerando os achados positivos em indivíduos hígidos ou sem evidência de auto-imunidade, que variam de $10 \%$ a 15\% nas diferentes casuísticas, fica evidente a necessidade de solicitações respaldadas em elementos clínicos ou 
laboratoriais sugestivos de auto-imunidade. A solicitação indiscriminada de ANA-IFI tem ocasionado situações conflitantes quando resultados positivos são confrontados com dados clínicos inconsistentes. A adequada interpretação dos padrões de IFI exerce papel primordial na valorização dos resultados encontrados. Características intrínsecas do teste ANA-HEp-2 podem ser úteis nesse sentido. O título do ANA-HEp-2 é um parâmetro de valor relativo, enquanto o padrão de fluorescência pode ter impacto mais decisivo. Isso é especialmente verdadeiro na presença de alguns pa- drões, como os PG e Ho, mais freqüentemente associados a estados auto-imunes sistêmicos, e de nucleares pontilhado fino denso e pontilhado grosso reticulado, presentes preferencialmente em indivíduos hígidos e em pacientes sem evidências de auto-imunidade. Entre esses, salienta-se o padrão nuclear pontilhado fino denso, por seu reconhecimento relativamente recente e por representar o padrão observado mais freqüentemente e em maiores títulos em indivíduos não auto-imunes.

\section{Referências}

I. AARDEN, L.A. et al. Detection of antibodies to DNA by radioimmunoassay and immunofluorescence. Scand J Rheumatol, Suppl I I, p. 12-9, 1975.

2. ANDERSON, J.R. et al. Precipitating antibodies in the connective tissue diseases. Ann Rheum Dis, v. 21, p. 360-9, 1962.

3. ANDRADE, L.E. et al. Human autoantibody to a novel protein of the nuclear coiled body: immunological characterization and cDNA cloning of p80 coilin. J Exp Med, v. 173, p. |407-19, 199|.

4. ANDRADE, L.E.C. Como valorizar os resultados de teste de FAN (anticorpos antinúcleo) e suas diferentes metodologias. Sinopses em Reumatologia, v. 4, p. 3-9, 2002.

5. ARBUCKLE, M.R. et al. Development of autoantibodies before the clinical onset of systemic lupus erythematosus. N Engl J Med, v. 349, p. 1526-33, 2003.

6. BENITO-GARCIA, E. et al. The American College of Rheumatology Ad Hoc Committee on Immunologic Testing Guidelines. Guidelines for Immunologic Laboratory Testing in the Rheumatic Diseases: anti-Sm and anti-RNP antibody tests. Arthritis Rheum, v. 5I, p. 1030-44, 2004.

7. BEYNE-RAUZY, O. et al. Anti-PCNA antibodies: prevalence and predictive value. Joint Bone Spine, v. 72, n. 5, p. 432-5, 2005.

8. CIMOLAI, N.; MAH, D.; ROLAND, E. Anticentriolar autoantibodies in children with central nervous system manifestations of Mycoplasma pneumoniae infection.J Neurol Neurosurg Psychiatry, v. 57, n.5, p. 638-9, 1994.

9. COONS, A.H.; KAPLAN, M.H. Localization of antigen in tissue cells: II. Improvements in a method for the detection of antigen by means of fluorescent antibody. J Exp Med, v. 91. p. I-13, 1950.

10. COOPER, G.M. Estrutura e função celular - domínios funcionais dentro do núcleo. In: COOPER, G.M., editor. A Célula - uma abordagem molecular. 2 ed. Porto Alegre: Artmed Editora, 2002. p. $712: 356$.

I I. DEANE, P.M.G. et al. The outcome of children referred to a pediatric rheumatology clinic with a positive antinuclear antibody test but without an autoimmune disease. Pediatrics, v. 95, p. 892, 1995.
12. DellaVANCE, A. et al. II Consenso Brasileiro de Fator Antinuclear em Células HEp-2. Definições para padronização da pesquisa contra constituintes do núcleo, nucléolo, citoplasma e aparelho mitótico e suas associações clínicas. Rev Bras Reum, v. 43, p. 129-40, 2003.

13. DELLAVANCE, $A$. et al. The clinical spectrum of antinuclear antibodies associated with the nuclear dense fine speckled immunofluorescence pattern. J Rheumatol, v. 32, n. I I, p. 2। 44-9, 2005.

14. FATHI, M. et al. Interstitial lung disease, a common manifestation of newly diagnosed polymyositis and dermatomyositis. Ann Rheum Dis, v. 63, p. 297-30I, 2004.

15. FERNANDEZ, S.A.V. et al. Prevalence of antinuclear autoantibodies in the serum of normal blood donors. Rev Hosp Clin Fac Med S. Paulo, v. 58, p. 31 5-9, 2003.

16. FORSLID, J. et al. The prevalence of antinuclear antibodies in healthy young persons and adults, comparing rat liver tissue sections with HEp-2 cells as antigen substrate. Clin Exp Rheumatol, v. 12, p. 137-41, 1994.

17. FRITZLER, M.J. et al. Antinuclear, anticytoplasmic, and antiSjögren's syndrome antigen A (SS-A/Ro) antibodies in female blood donors. Clin Immunol Immunopathol, v. 36, p. 120-8, 1985.

18. GONZALES, C. et al. Anti-nucleosome, anti-chromatin, antidsDNA and anti-histone antibody reactivity in systemic lupus erythematosus. Clin Chem Lab Med, v. 42, p. 266-72, 2004

19. GOTO, N. et al. Anti-p80 coilin autoantibodies react with a conserved epitope and are associated with anti-DSF70/LEDGF autoantibodies.J Autoimmun, v. 26, n. I, p. 42-51. 2006

20. HARGRAVES, M.; RICHMOND, M.; MORTON, R. Presentation of two bone marrow elements: the "tart" cell or LE cell. Mayo Clin Proc, v. 23, p. 25-8, 1948.

21. HARMON, C.E.; DENG, J-S.; PEEBLES, C.L. The importance of tissue substrate in the SS-A/Ro antigen-antibody system. Arthritis Rheum, v. 27, p. 166-73, 1984.

22. HILARIO, M.O. et al. Frequency of antinuclear antibodies in healthy children and adolescents. Clin Pediatr, v. 43, p. 637-42, 2004. 
23. HO, K.T.; REVEILLE, J.D.The clinical relevance of autoantibodies in scleroderma. Arthritis Res Ther, v. 5, p. 80-93, 2003.

24. HOCHBERG, M.C. Updating the American College of Rheumatology revised criteria for the classification of systemic lupus erythematosus [letter]. Arthritis Rheum, v. 40, p. $1725,1997$.

25. INOKUCHI, T. et al. Retroperitoneal ancient schwannoma presenting as an adrenal incidentaloma: CT and MR findings. Magn Reson Imaging, v. 24, p. I389-93, 2006.

26. LACROIX-DESMAZES, S. et al. Self-reactive antibodies (natural autoantibodies) in healthy individuals. I Immunol Methods, v. 216, p. 117-37, 1998.

27. LAURINO, C.F.C. et al. Human autoantibodies to diacylphosphatidylethanolamine recognize a specific set of discrete cytoplasmic domains. Clin Exp Immunol, v. I43, n. 572-84, 2006.

28. LESER, P.G. et al. Distinctive features of antinuclear antibodies observed in health and in subjects with autoimmune rheumatic diseases. In: CONRAD, K. et al. (org.). From animal models to human genetics: research on the induction and pathogenicity of autoantibodies. Dresden: Pabst Science Publishers, 2004. p. 493-510.

29. MASSABKI, P.S. et al. Clinical implications of autoantibodies in HIV infection. AIDS, v. I I, p. I845-50, 1997.

30. MIGLIORINI, P. et al. Anti-Sm and anti-RNP antibodies. Autoimmunity, v. 38, p. 47-54, 2005.

3I. REIMER, G. et al. Correlates between autoantibodies to nucleolar antigens and clinical features in patients with systemic sclerosis (scleroderma). Arthritis Rheum, v. 31, p. 525-32, 1988

32. ROKEACH, I.A.; HOCH, S.O. B-cell epitopes of Sm autoantigens. Mol Biol Reports, v. 16, p. 165-74, 1992.

33. SANTOS, L.M. et al. Prevalência e valor prognóstico de anticorpos antinucleares em indivíduos idosos. Rev Bras Reumatol, v. 37, p. 323-8, 1997.

34. SHINOHARA, T.; SINGH, D.P.; FATMA, N. LEDGF, a survival factor, activates stress-related genes. Prog Retin Eye Res, v. 2I, p. 34I-58, 2002.

35. SILVA, N.P. et al. Desenvolvimento de ensaio imunoenzimático (ELISA) para detecção de anticorpos anti-DNA nativo usando DNA de Crithidia luciliae como substrato. Rev Bras Reumatol, v. 35, p. I83-8, 1995.

36. SZANTO, A. et al. Clinical, serologic, and genetic profiles of patients with associated Sjogren's syndrome and systemic lupus erythematosus. Hum Immunol, v. 67, n. I I, p. 924-30, 2006.

37. TAKASAKI, Y. Anti-PCNA antibody. Nippon Rinsho, v. 57, Suppl, p. 456-8, 1999.

38. TAN, E.M. et al. Range of antinuclear antibodies in "healthy" individuals. Arthritis Rheum, v. 40, n. 9, p. 1601-11, 1997.

39. TAN, E.M. et al.The 1982 revised criteria for the classification of systemic lupus erythematosus. Arthritis Rheum, v. 25, p. |27|-7, 1982.

40.VAILE, J.H. et al. Is high titer ANA specific for connective tissue disease? Clin Exp Rheumatol, v. 18, p. 433, 2000.

4I. WATANABE, A. et al. Anti-DFS70 antibodies in 597 healthy hospital workers. Arthritis Rheum, v. 50, p. 892-900, 2004. 